\title{
Concrete Carbonation and Chloride Resistance Under Initial Hot Water Curing
}

\author{
G. Li, X. L. Li, R. R. Wei, J. M. Du, and X. S. Wu \\ Jiangsu Key Laboratory of Environmental Impact and Structural Safety in Engineering, \\ China University of Mining \& Technology
}

\begin{abstract}
Three concrete mix proportions were designed and prepared, respectively, such as fly ash concrete (abbreviated as "FAC") with $30 \%$ fly ash replacement ratio of cement, fly ash, and slag concrete (abbreviated as "FSC") with each of $20 \%$ fly ash and slag replacement ratio and ordinary Portland cement concrete (abbreviated as "OPC") for the research of carbonation and chloride resistance of concrete under different initial hot water curing. Specimens with precuring were put into $20^{\circ} \mathrm{C}$ water tank for curing firstly until a certain compressive strength of $14 \mathrm{MPa}$ reached after demolding, while specimens without precuring were put into 40,60 , and $80^{\circ} \mathrm{C}$ water tanks for curing directly just after demolding. Hot water curing of each specimen was finished when the designed compressive strength of $35 \mathrm{MPa}$ was reached, then specimens were taken out into indoor natural environment. High concentration $\mathrm{CO}_{2}$ carbonation and Coulomb electric flux experiments were carried out at specimens' 100-day age. Results show that with the addition of fly ash or slag, the carbonation resistance of concrete declines, whereas the resistance to chlorides is improved. With the increasing of initial water-curing temperature from 40 to $80^{\circ} \mathrm{C}$, the carbonation and chloride resistance of OPC concrete all decrease, whereas for FAC and FSC concretes, the carbonation resistance declines and chloride resistance goes up. Precuring at the normal temperature before the elevated temperature water curing is beneficial for concrete long-term carbonation and chloride resistance.
\end{abstract}

As one of the hydraulic cementing materials, concrete needs suitable environment temperature and humidity for its setting and hardening. Initial curing conditions not only determine the development of concrete mechanical properties but also concrete micropore structures and long-term durability performances (Haque, Al-Khaiat, \& Kayali, 2007; Shafig \& Cabrera, 2004). Elevated temperature curing is always one of the important curing methods for prefabricated concrete elements, which can shorten the curing time needed, realize concrete strength designed, and increase the production efficiency. At the same time, it is also recognized that initial high temperature curing will play adverse effects on concrete long-term mechanical properties (Abd-El Aziz, Abd El Aleem, \& Mohamed Heikal, 2012; Balendran \& Martin-Buades, 2000; Sha \& Huang, 2011a). However, it has still no consistent conclusions about initial high temperature curing on concrete durability performances (Das \& Pandey, 2011; Lo, Nadeem, Tang, \& Yu, 2009; Mehta \& Gerwick, 1982; Ramezanianpour, Khazali, \& Vosoughi, 2013; Yazıcı, Aydın, Yiğiter, \& Baradan, 2005).

Mehta and Gerwick (1982) investigated the San Mateo bridge over San Francisco bay after being exposed for 17 years in the environment, which is composed of both steam-cured and moist-cured concrete beams with the same mixture proportions and materials. The study demonstrated that steam-cured beams had to be repaired according to the corrosion damage, while moist-cured beams showed no signs of deterioration. Other studies also illustrated that accelerated curing by excessively increased temperature leads to porous concrete with coarse and continuous pore structure and heterogeneous distribution of hydration products. Consequently, it increases the permeability of concrete against carbonation and aggressive ions, such as chlorides or sulfates (Lo et al., 2009; Ramezanianpour et al., 2013). However, with the addition of pozzolanic materials, such as silica fume, fly ash, or slag, to Portland cement, it is known that its heat resistance is improved (Das \& Pandey, 2011; Feng, Chen, Ye, et al., 2010; Tan \& Liu, 2006; Yazıcı et al., 2005). Lu, $\mathrm{Li}$, Yuan, et al. (2011) studied the carbonation of fly ash concrete cured in 20,30 , and $40^{\circ} \mathrm{C}$ water for $3,7,14$, and 28 days, respectively, and found that prolonging initial curing time and increasing curing temperature is beneficial for concrete carbonation resistance. For the same curing conditions, carbonation rate of fly ash concrete is usually higher than OPC concrete, but with the increase of initial curing temperature, the difference can be reduced. Sha \& Huang (2011b) studied the effects of precuring on steam-cured concrete durability and found that the frost resistance, impermeability, and carbonation resistance of concrete without precuring decreased more greatly than that of concrete with precuring. It suggests that precuring has significant effects on concrete durability after steam curing. 
To the authors' knowledge, it is still very limited of research works carried out on the effects of elevated temperature curing on concrete long-term durability. Concrete carbonation and chloride resistance are its important durability performances. The objective of this paper is to minimize or avoid the negative effects of initial hot water curing on concrete long-term carbonation and chloride resistance through some measures, such as addition of mineral admixtures, changing the initial conditions before hot water curing, or setting the temperature upper limit of hot water curing.

\section{EXPERIMENTAL}

\subsection{Raw materials}

Three mixtures of concrete were designed, which are fly ash concrete with $30 \%$ substitution ratio, fly ash, and ground granulated slag concrete with each of $20 \%$ substitution ratio, and ordinary Portland cement concrete. Class I low calcium fly ash and S105 grade ground granulated slag were adopted and used, and their chemical composition is shown in Table 1.P.O42.5 ordinary Portland cement, natural river sand, crashed stone with particle sizes in 5-20 mm, and tap water were also utilized. In addition to a kind of naphthalene series, high efficient water-reducing agent was used. The water/cement ratio was 0.54 , and the designed compressive strength was $35 \mathrm{MPa}$. Detailed concrete mixture proportions are shown in Table 2.

Table 1. Chemical composition of fly ash and slag/\%.

\begin{tabular}{lccccccc}
\hline Item & $\mathrm{SiO}_{2}$ & $\mathrm{Al}_{2} \mathrm{O}_{3}$ & $\mathrm{Fe}_{2} \mathrm{O}_{3}$ & $\mathrm{CaO}$ & $\mathrm{MgO}$ & $\mathrm{SO}_{3}$ & $\begin{array}{l}\text { Loss on } \\
\text { Ignition }\end{array}$ \\
\hline Fly ash & 57.2 & 30.3 & 4.5 & 2.5 & 0.6 & 0.45 & 2.65 \\
Slag & 32.3 & 15.5 & 2.4 & 44.1 & 0.4 & 0.3 & 2.31 \\
\hline
\end{tabular}

Table 2. Concrete mixture proportion $/ \mathrm{kg} / \mathrm{m}^{3}$.

\begin{tabular}{lccc}
\hline Item & $\begin{array}{c}\text { OPC } \\
\text { Concrete }\end{array}$ & $\begin{array}{c}\text { FAC } \\
\text { Concrete }\end{array}$ & $\begin{array}{c}\text { FSC } \\
\text { Concrete }\end{array}$ \\
\hline Cement & 398 & 279 & 239 \\
Fly ash & 0 & 119 & 80 \\
Slag & 0 & 0 & 80 \\
River sand & 680 & 680 & 680 \\
Crashed stone & 1157 & 1157 & 1157 \\
Water & 215 & 215 & 215 \\
Water reducer & 7.5 & 7.5 & 7.5 \\
\hline
\end{tabular}

\subsection{Fabrication of concrete specimens and curing methods}

Concrete was mixed by a forced mixer, and specimens were demolded $24 \mathrm{~h}$ after casting. Before entering the hot water curing, to obtain certain compressive strength of $14 \mathrm{MPa}$, specimens with precuring were put into $20^{\circ} \mathrm{C}$ water for $0.6,1.1$, and 1.8 days for
OPC, FAC, and FSC concretes, respectively, after demolding, whereas specimens without precuring were put into hot water tanks of three temperatures, such as 40,60 , and $80^{\circ} \mathrm{C}$ just after demolding. Curing time for each specimen is based on its designed compressive strength of $35 \mathrm{MPa}$, which was determined by the experimental results made already and shown in Table 3. Water temperature of each water tank is kept constant during the whole curing period. Curing in $20^{\circ} \mathrm{C}$ water for 28 days was also adopted for comparison. After curing, specimens were taken out into indoor natural atmospheric environment.

Table 3. Hot water curing time of specimens/day.

\begin{tabular}{lccc}
\hline Item & $\begin{array}{c}\text { Water Curing } \\
\text { Temperature }{ }^{\circ} \mathrm{C}\end{array}$ & \multicolumn{2}{c}{ Water Curing Time/Day } \\
\cline { 3 - 4 } & & $\begin{array}{c}\text { Without } \\
\text { Precuring }\end{array}$ & $\begin{array}{c}\text { With } \\
\text { Precuring }\end{array}$ \\
\hline OPC concrete & 40 & 8.0 & 7.0 \\
& 60 & 6.0 & 5.0 \\
& 80 & 4.0 & 3.8 \\
\hline FAC concrete & 40 & 9.0 & 8.5 \\
& 60 & 5.5 & 4.0 \\
& 80 & 3.1 & 2.8 \\
\hline FSC concrete & 40 & 9.0 & 8.5 \\
& 60 & 5.0 & 4.0 \\
& 80 & 2.8 & 2.8 \\
\hline
\end{tabular}

Considering the lag effects of pozzolanic reaction of mineral admixture adulterated in concrete, and to fully reflect the initial water-curing conditions on concrete long-term durability performances, concrete carbonation and chloride resistance experiments were carried out at their 100-day age. Both high concentration $\mathrm{CO}_{2}$ accelerated carbonation experiment and Coulomb electric flux experiment were carried out and based on the stand for test methods of long-term performance and durability of ordinary concrete of China (GB/T50082-2009).

\subsection{Carbonation experiment}

Size of specimens for carbonation is $100 \mathrm{~mm} \times$ $100 \mathrm{~mm} \times 300 \mathrm{~mm}$. Specimens were put into $60^{\circ} \mathrm{C}$ oven $48 \mathrm{~h}$ for drying first when they reached 100-day age, then put into a high concentration $\mathrm{CO}_{2}$ carbonation box for carbonation for 7 days, in which the carbonation conditions, such as $\mathrm{CO}_{2}$ concentration of $20 \pm 3 \%$, relative humidity of $70 \pm 5 \%$, and temperature of $20 \pm 2{ }^{\circ} \mathrm{C}$, were kept constant. Specimens were taken out after carbonation and split into two pieces and sprayed at the fresh section by $5 \%$ ethanol phenolphthalein solution. Carbonation depth of each specimen was measured by a steel rule. The average value of three specimens was taken as the representative value of carbonation depth value. 


\subsection{Coulomb electric flux experiment}

Specimens for Coulomb electric flux experiment are $100 \mathrm{~mm}$ diameter and $200 \mathrm{~mm}$ high cylinders. Using a rock cutting machine, specimens were cut off the two ends of about $25 \mathrm{~mm}$ length first and then cut into three pieces of $50 \mathrm{~mm}$ height, then soaked in distilled water for $24 \mathrm{~h}$ in a vacuumed water tank, after that placed into a standard Coulomb electric flux experimental device for test. Specimens were applied to $60 \mathrm{~V}$ direct current and kept for $6 \mathrm{~h}$. During test current intensity through each specimen was recorded periodically. According to Equation (1), Coulomb electric flux $Q$ of each specimen can be calculated. The average value of three specimens was taken as the representative value:

$$
Q=900\left(I_{0}+2 I_{30}+2 I_{60}+\cdots+2 I_{330}+I_{360}\right)
$$

In which, $I_{0}, I_{30}, I_{60}, \ldots$ means the current intensity corresponded at the subscript moment, accurate to milliampere.

\section{EXPERIMENTAL RESULTS AND ANALYSIS}

\subsection{Influences of water-curing temperature on concrete carbonation depth}

Based on the data obtained, concrete carbonation depth of three sorts of concrete specimens under different initial water-curing conditions is shown, respectively, in Figures $1-3$, in which data of $20^{\circ} \mathrm{C}$ are obtained from specimens cured in $20^{\circ} \mathrm{C}$ water.

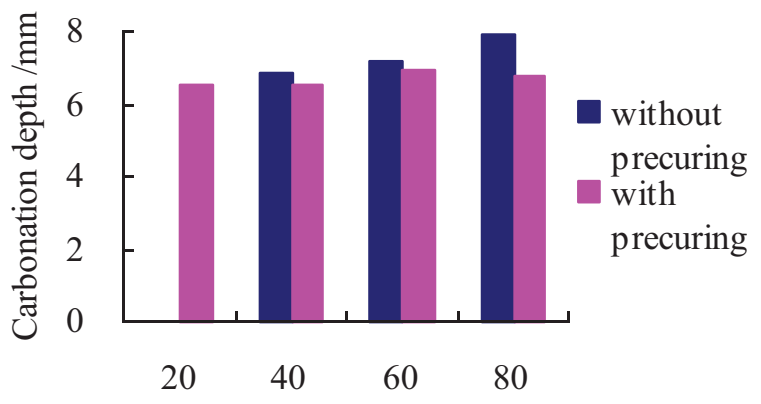

Water curing temp erature $/{ }^{\circ} \mathrm{C}$

Figure 1. Carbonation depth of OPC specimens.

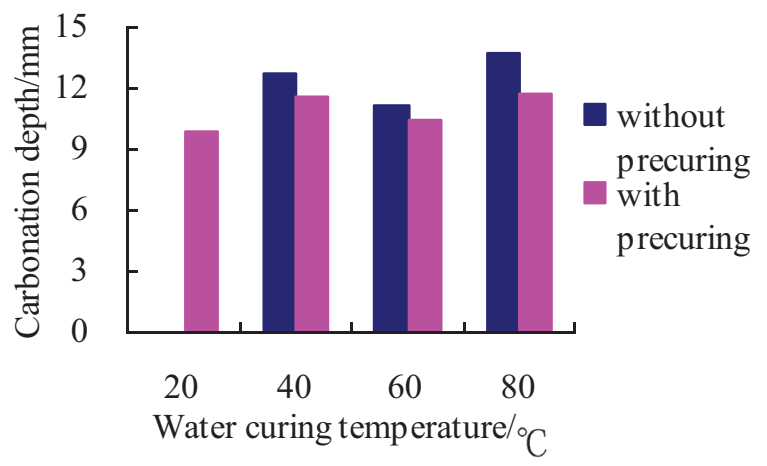

Figure 2. Carbonation depth of FAC specimens.

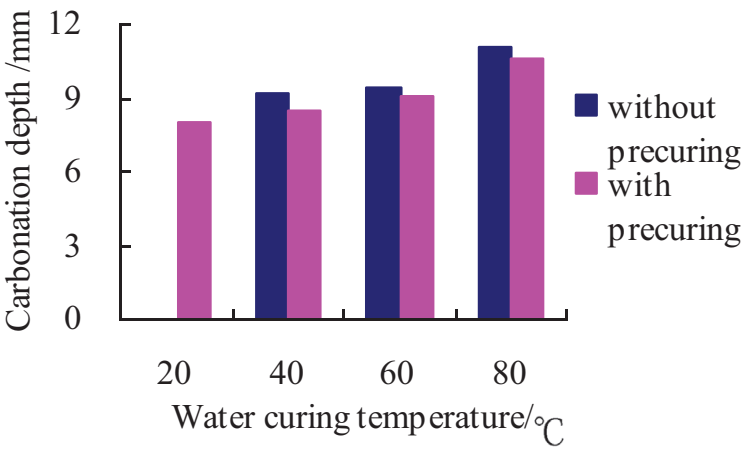

Figure 3. Carbonation depth of FSC specimens.

Precuring is that concrete accepts a normal temperature curing for a period first before starting elevated temperature curing (Sha \& Huang, 2011b). It is usually aimed to let concrete obtaining certain strength before it enters high temperature curing, which is beneficial for concrete to resist the internal thermal stress caused by high temperature curing process. There are obvious effects of initial water-curing temperature and precuring on concrete carbonation depths of three composition specimens from Figures 1-3. Concrete carbonation depths of specimens with precuring are found always lower than that of specimens without precuring, which reflects precuring is prone to improve concrete capability of anticarbonation, while the influences of initial curing temperature on concrete carbonation depths are different according to different raw materials composition.

For the same concrete mixture, specimens cured in $20^{\circ} \mathrm{C}$ water have the lowest carbonation depth, which suggests the best carbonation resistance. With the increasing of initial curing temperature from 20 to $80^{\circ} \mathrm{C}$, concrete carbonation depths goes up gradually, which means carbonation resistance goes down. Meanwhile, the negative effects of initial high temperature curing can be partly compensated through precuring at $20^{\circ} \mathrm{C}$ water. The process of precuring will promote the hydration degree of cementitious materials, increase concrete strength, and improve concrete internal microscopic pore structures for both OPC concrete and FAC and FSC concretes. On the contrary, the hydration degree is relatively lower for concrete specimens without precuring, and the internal microscopic pore structures are not fixed. With the proceeding of elevated temperature water curing, unhydrated cementitious materials hydrate quickly. The morphology and distribution of hydration products under high temperature curing are different from that under normal temperature curing (Escalante-García \& Sharp, 2001; Li et al., 2011), which is mainly because that the higher of the curing temperature, the faster of the speed of the cementitious materials' hydration reaction, the larger of the size of new products generated. The 
dissolution rate of the film or its transfer speed of new creatures to free water is relatively slow, so the film will gradually thickening, which hinders the free water seeping into the membrane and cement particles continue to hydrate, leading the internal microscopic pore structures of concrete bulky and crystal more divergent and uneven, so as to weaken concrete carbonation resistance. Changes of specimens with precuring are smaller when subjected to elevated temperature water curing than specimens without precuring, so it results in specimens with precuring were usually carbonated less depth than specimens without precuring.

The pozzolanic reaction of fly ash or slag needs to consume $\mathrm{Ca}(\mathrm{OH})_{2}$, which will lead to concrete carbonation resistance decline. In slag chemical composition, there are more $\mathrm{CaO}$ content than that in fly ash, so the consumption of $\mathrm{Ca}(\mathrm{OH})_{2}$ is less in FSC concrete than that in FAC concrete. In addition, due to the microstructure damages caused by initial elevated temperature curing, among these three concrete mixtures, the anticarbonation capability of OPC concrete behaves the best, FSC concrete is the second, and FAC concrete is the worst.

For OPC and FSC concrete specimens, with the increasing of initial water-curing temperature from 40 to $80^{\circ} \mathrm{C}$, both specimens show rising carbonation depths. It means elevated temperature water curing will cause concrete carbonation resistance decline, and the higher the initial curing temperature, the lower the concrete carbonation resistance is. However, the situation is slightly different for FAC concrete specimens. With the rising of initial water-curing temperature from 40 to $60^{\circ} \mathrm{C}$ and from 60 to $80^{\circ} \mathrm{C}$, concrete carbonation depths behave rising after initial falling. This indicates that carbonation resistance of FAC concrete behaves increasing at the range of $40-60^{\circ} \mathrm{C}$ but decreasing at the range of $60-80^{\circ} \mathrm{C}$. Reasons of above phenomena can be summed up that the pozzolanic activity of fly ash is very low, and high temperature can stimulate fly ash pozzolanic activity, promote its hydration reaction speed, increase the hydration degree, and improve the micropore structures of concrete further. It is helpful to make up the adverse effects caused by initial hot water curing. However, for the same reason, excessive high temperature $\left(80^{\circ} \mathrm{C}\right)$ can also bring about adverse effects that cause fly ash concrete carbonation resistance decline again.

\subsection{Influences of water-curing temperature on concrete chloride resistance}

Figures 4-6 give the Coulomb electric flux of three kinds of concrete specimens under different initial curing conditions, in which data of $20^{\circ} \mathrm{C}$ are from specimens cured in $20^{\circ} \mathrm{C}$ water.

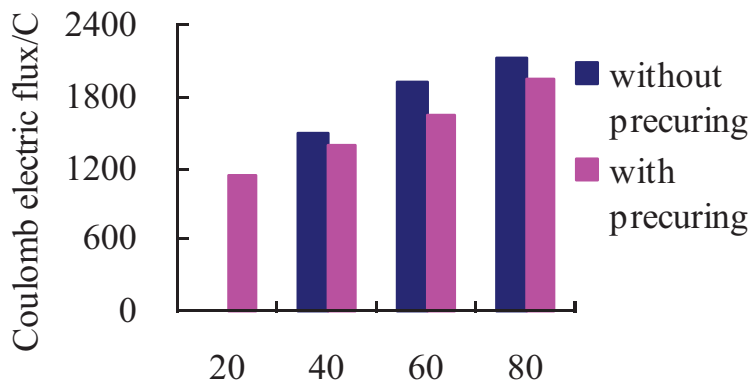

Water curing temp erature $/{ }^{\circ} \mathrm{C}$

Figure 4. Coulomb electric flux of OPC specimens.

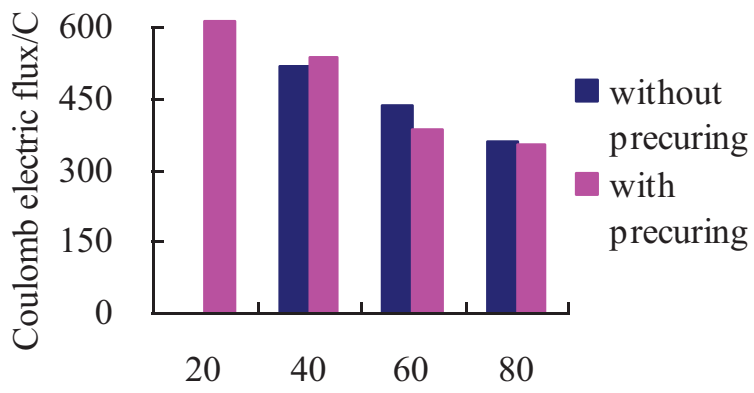

Water curing temp erature $/{ }^{\circ} \mathrm{C}$

Figure 5. Coulomb electric flux of FAC specimens.

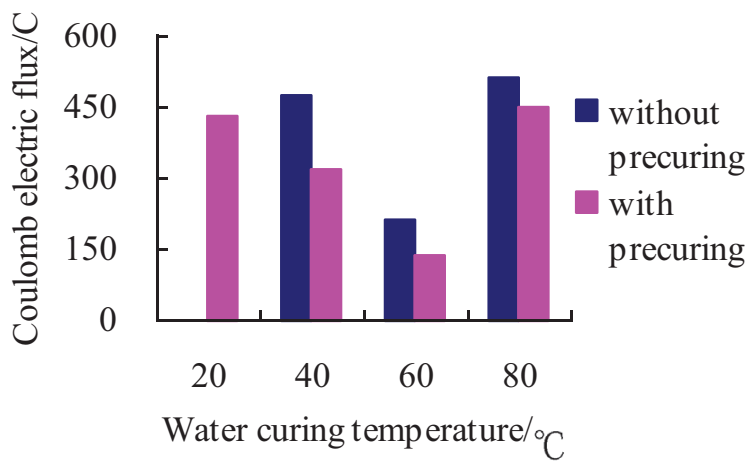

Figure 6. Coulomb electric flux of FSC specimens.

As can be seen from Figures 4-6, there are significant effects of the initial water-curing temperature on concrete Coulomb electric flux, and it changes a lot with concrete raw materials composition and whether it is precured. With the addition of fly ash or slag, concrete Coulomb electric fluxes are significantly decreased. For specimens cured in $20 \mathrm{C}$ water, Coulomb electric flux of FAC concrete is about half of OPC concrete, and that of FSC concrete is nearly one-third of OPC concrete. This indicates that adding fly ash or slag into concrete is prone to enhance concrete obtaining high chloride resistance, which is consistent with results obtained in existed research (Feng et al., 2010; Li, Lei, \& Du, 2013).

No matter OPC concrete specimens but also FAC and FSC concrete specimens, the process of precuring 
at normal temperature before hot water curing can increase concrete initial compressive strength, improve its microstructure, and then reduce concrete Coulomb electric flux in a certain degree like that on concrete carbonation resistance, that is, improve the capability of chloride penetration resistance of concrete. It indicates precuring is beneficial to improve concrete chloride resistance. However, at the same time, the improvement degrees of precuring for OPC, FAC, and FSC concretes are different, in which OPC concrete is the highest, FSC concrete is the second, and FAC concrete is the third.

For OPC concrete, effects of elevated temperature curing on Coulomb electric flux are similar with that on carbonation resistance, which are all negative effects. Coulomb electric flux of OPC concrete cured in $20^{\circ} \mathrm{C}$ water is the lowest, and it increases gradually with the increasing of water-curing temperature. But it is just the opposite for FAC concrete specimens. Coulomb electric flux of FAC concrete cured in $20^{\circ} \mathrm{C}$ water is the highest, and it decreases gradually with the increasing of water-curing temperature. As for FSC concrete, it appears decrease with the water-curing temperature from 40 to $60^{\circ} \mathrm{C}$ and then increase with the watercuring temperature from 60 to $80^{\circ} \mathrm{C}$ like a wavy. This reflects that initial water-curing temperatures will cause different influences on concrete chloride resistance along with different concrete composition.

For FAC and FSC concretes, increasing water-curing temperature can stimulate the pozzolanic activity of fly ash or slag, improve the hydration degree, and make concrete denser, which is beneficial to promote concrete chloride resistance (Li et al., 2011). But it is known that the pozzolanic activity of slag is higher than that of fly ash, so with the increasing of water-curing temperature, negative impacts of high temperature curing emerge gradually, and it makes chloride resistance of $\mathrm{FSC}$ concrete cured at $80^{\circ} \mathrm{C}$ down.

\section{CONCLUSIONS}

Based on the experimental results and theoretical analysis, some conclusions can be drawn as the following:

(1) With the addition of fly ash and ground granulated slag, concrete carbonation resistance tends to decline gradually, but chloride resistance tends to increase gradually. It is more beneficial of the improvement of carbonation and chloride resistance for concrete adulterated both fly ash and slag than only fly ash.

(2) Concrete cured in $20^{\circ} \mathrm{C}$ water can obtain the highest carbonation resistance. With the increasing of water-curing temperature from 20 to $80^{\circ} \mathrm{C}$, the carbonation resistance of OPC and FSC concrete is prone to decline gradually in general, while for FAC concrete, its behavior is between OPC and FSC concrete, increase before $60^{\circ} \mathrm{C}$ and then decline after $60^{\circ} \mathrm{C}$.

(3) With the increasing of water-curing temperature from 20 to $80^{\circ} \mathrm{C}$, chloride resistance of $\mathrm{OPC}$ concrete tends to decline gradually, but FAC concrete behaves the opposite. For FSC concrete, its behavior is between OPC and FAC concretes, decline before $60^{\circ} \mathrm{C}$ and then increase after $60^{\circ} \mathrm{C}$.

(4) Precuring of concrete at normal temperature before starting elevated temperature curing is helpful to enhance carbonation and chloride resistance for both OPC concrete and FAC and FSC concretes.

\section{ACKNOWLEDGMENTS}

This paper is financially funded by China National Natural Science Foundation (No. 51178455) and open fund project of Jiangsu Province Key Laboratory (No. JSKL2012YB01).

\section{REFERENCES}

Abd-El Aziz, M. A., Abd El Aleem, S., \& Mohamed Heikal. (2012). Physico-chemical and mechanical characteristics of pozzolanic cement pastes and mortars hydrated at different curing temperatures [J]. Construction and Building Materials, 26(1), 310-316.

Balendran, R. V., \& Martin-Buades, W. H. (2000). The influence of high temperature curing on the compressive, tensile and flexural strength of pulverized fuel ash concrete [J]. Building and Environment, 35(5), 415-423.

Das, B. B., \& Pandey, S. P. (2011). Influence of fineness of fly ash on the carbonation and electrical conductivity of concrete [J]. Journal of Materials in Civil Engineering, 23(9), 1365-1368.

Escalante-García, J. I., \& Sharp, J. H. (2001). The microstructure and mechanical properties of blended cements hydrated at various temperatures [J]. Cement and Concrete Research, 31(5), 695-702.

Feng, N. Q., Chen, L. X., Ye, H. W., et al. (2010). Design and application of high performance and super-high performance concrete pipe pile [J]. Concrete and Cement Product, (6), 25-28.

Haque, M. N., Al-Khaiat, H., \& Kayali, O. (2007). Long-term strength and durability parameters of lightweight concrete in hot regime: Importance of initial curing [J]. Building and Environment, 42(8), 3086-3092.

Li, G., Lei, M., \& Du, J.M. (2013). Design of anticorrosion of a reinforced concrete cooling tower with flue gas injection [J]. Concrete, 9, 133-136. 
Li, G., Lu, E. L., Wang, P., Geng, O., \& Ji, Y. (2011). Influences of initial curing conditions on the microstructure of fly ash cement system [J]. Advanced Materials Research, 168-170, 532-536.

Lo, T. Y., Nadeem, A., Tang, W. C. P., \& Yu, P. C. (2009). The effect of high temperature curing on the strength and carbonation of pozzolanic structural lightweight concretes [J]. Construction and Building Materials, 23(3),1306-1310.

Lu, E. L., Li, G., Yuan, Y., Geng, O., \& Du, J. (2011). Studies about the initial curing conditions on the carbonation resistance of fly-ash concrete [J]. Advanced Materials Research, 250-253, 920-924.

Mehta, P. K., \& Gerwick, B. (1982). Crackingcorrosion interaction in concrete exposed to marine environment [J]. Concrete International, 4(10), 45-51. Ramezanianpour, A. A., Khazali, M. H., \& Vosoughi, P. (2013). Effect of steam curing cycles on strength and durability of SCC: A case study in precast concrete [J]. Construction and Building Materials, 49, 807-813.
Sha, K., \& Huang, Y. C. (2011a). Influence of precuring time on steam curing concrete durability [J]. Low Temperature Architecture Technology, 2011(7), 15-16.

Sha, K., \& Huang, Y. C. (2011b). Influence of steam curing time on fly ash concrete compressive strength [J]. Low Temperature Architecture Technology, 2011(8), 7-8.

Shafig, N., \& Cabrera, J. G. (2004). Effects of initial curing condition on the fluid transport properties in OPC and fly ash blended cement concrete [J]. Cement and Concrete Composites, 26, 381-387.

Tan, K. F., \& Liu, T. (2006). Effect of high temperature curing on compressive strength of concrete [J]. Journal of Building Materials, 9(4), 473-476.

Yazıcı, H., Aydın, S., Yiğiter, H., \& Baradan, B. (2005). Effect of steam curing on class $C$ highvolume fly ash concrete mixtures [J]. Cement and Concrete Research, 35(6), 1122-1127. 